\title{
Avaliação da segurança viária pela percepção do cidadão francano: estudo de caso das principais avenidas, localizadas na cidade de Franca / SP
}

\author{
Fernando Luis Velazquez, Leonardo Suave, \\ Túlio Benetti Simari, Tassiane de Paula \\ Pinheiro Coelho*
}

\begin{abstract}
Resumo O estudo aborda a cidade de Franca/SP, que chamou a atenção pelo elevado número de acidentes com vítimas fatais no ano de 2018: cerca de 39 mortes registradas. Um dos principais fatores para esse estudo foi o excesso de velocidades nas vias. Diante disso, o estudo tem como objetivo avaliar 7 das 28 avenidas principais da cidade e propor soluções, para o desenvolvimento do trânsito mais otimizado e seguro. A metodologia foi baseada na avaliação da percepção dos usuários das avenidas abordadas, em relação a segurança do trânsito proporcionada aos pedestres, motociclistas e motoristas, por meio de entrevistas pessoais e online. Os resultados obtidos informaram que $37 \%$ dos entrevistados sofreram pelo menos um acidente, totalizaram em 106 ocorrências.
\end{abstract}

Palavras-chave: acidentes, segurança, trânsito.

\section{Evaluación de la seguridad vial por la percepción del ciudadano francano: estu- dio de caso de las principals avenidas, ubicado en la ciudad de Franca / SP}

\footnotetext{
Resumen El estudio se dirige a la ciudad de Franca / SP, que llamó la atención por elevado número de accidentes con víctimas mortales en 2018: unas 39 muertes registradas. Uno de principales factores de este estudio fue exceso de velocidad en carreteras. Por tanto, el estudio tiene como objetivo evaluar 7 de las 28 principales avenidas de ciudad y proponer soluciones para desarrollo de un tráfico más optimizado y seguro. La metodología se basó en la evaluación de percepción de usuarios de avenidas abordadas, en relación a la seguridad vial brindada a peatones, motociclistas y conductores, a través de entrevistas personales y online. Los resultados obtenidos informaron que $37 \%$ de los entrevistados sufrió al menos un accidente, totalizando 106 ocurrencias.
}

Palabras clave: accidentes, seguridad, tráfico.
Evaluation of road safety by the perception of the francano citizen: study of the main avenues, location in the city of Franca / SP

\begin{abstract}
The study addresses the city of Franca / SP, which drew attention for the high number of accidents with fatal victims in 2018: about 39 registered deaths. One of the main factors for this study was the excess of speed on the roads. Therefore, the study aims to evaluate 7 of the 28 main avenues in the city and propose solutions for the development of more optimized and safe traffic. The methodology was based on the evaluation of the perception of users of the avenues addressed, in relation to the traffic safety provided to pedestrians, motorcyclists and drivers, through personal and online interviews. The results obtained reported that $37 \%$ of the interviewees suffered at least one accident, totaling 106 occurrences.
\end{abstract}

Keywords: accidents, safety, traffic. 

acordo com o Datasus - Ministério da Saúde (2014), anualmente, aproximadamente 40.000 pessoas morrem e cerca de 200.000 ficam feridas, devido aos acidentes de trânsito. Como foi mencionado, a ONU declarou o período da década da ação em prol da segurança no trânsito, diante disso, nasceu o Projeto Vida no Trânsito - PVT, iniciativa brasileira, com a finalidade de promover saúde e de prevenção de mortes e lesões no trânsito, de acordo com Ministério da Saúde (2017).

Na cidade em que se relata o estudo de caso, foi visto que no ano de 2017, cerca de 21 mortes foram causadas no trânsito, e apenas no início do ano de 2018, aproximadamente 17 mortes foram registradas, onde 11 são motociclista que representam em torno de $65 \%$ de vítimas fatais. (DEPARTAMENTO DE POLÍCIA MILITAR, 2018)

A maioria desses acidentes envolve o excesso de velocidade como fator não exclusivo, porém principal, há também relatado do consumo de álcool e o uso do celular, e diante desta situação abordada, o setor de Trânsito da Prefeitura de Franca/SP, juntamente com o Departamento Estadual de Trânsito de São Paulo - Detran, reforçam campanhas educativas, para minimizar o agravante no trânsito, com o aumento de segurança viária. Com isso o Departamento Estadual de Trânsito de São Paulo - Detran (2015) também relatou que "...pretende ampliar, ações para garantir mais segurança no trânsito de Franca que tem sido motivo de preocupação"

Algumas ações para solucionar certos problemas de trânsito são: (a) implementação de faixas elevadas com a intenção de reduzir a velocidade e aumentar a segurança e acessibilidade do pedestre; (b) inclusão de semáforos, semáforos com detectores de avanço de sinal vermelho; (c) aumento de sinalizações; (d) aumento de fiscalização como radares; (e) redução a exposição ao risco, ou seja, diminuir o tempo de viagens; ( $f$ ) engenharia do tráfego com implementação de novos projetos de rodovias, iluminação adequada; (g) aumento de conscientização em respeito a legislação, entre outros. (FERRAZ et. al, 2012; JORGE e MARTINS, 2013)

* Fernando Luis Velazquez é Arquiteto e Urbanista, Professor da Universidade de Franca, ORCID $<$ https://orcid.org/0000-00018230-5470>. Leonardo Suave é Engenheiro Civil, Universidade de Franca, ORCID <https:// orcid.org/0000-0002-79226197>. Túlio Benetti Simari é Engenheiro Civil, Universidade de Franca, ORCID <https://orcid. org/0000-0002-1192-5303>. Tassiane de Paula Pinheiro Coelho é Engenheira Civil, Professora da Universidade de Franca, ORCID $<$ https://orcid.org/0000-00025315-1764>.
Diante dos graves problemas enfrentados no trânsito, elevado número de mortes e feridos em decorrência da elevada taxa de acidentes, esse trabalho tem como objetivo principal avaliar avenidas de Franca, foco de alto volume de tráfego, em relação à segurança viária. Essa avaliação se pontuará por meio da percepção dos cidadãos francanos, com o intuito de proporcionar possíveis soluções, para se obter melhorias no trânsito, tanto na segurança quanto na educação.

Este estudo pretende gerar dados sobre a acidentalidade no trânsito em função da percepção dos moradores de Franca, com o propósito de contribuir em relação à segurança no trânsito. Além disso, levantar números de acidentes nas avenidas, a fim de difundir massivamente esse grave problema urbano, tendo como alvo principal aumentar a conscientização e educação no trânsito, para que se possa reverter o cenário atual. 
Figura 1: Tipos de acidentes no transito. Fonte: ABNT, 1989.

\section{Revisão de literatura}

\section{Aspectos sobre o trânsito francano}

O trânsito francano apresenta uma sinalização parcialmente regular seja por placas de sinalização (vertical), pintura do solo (horizontal),semáforos e redutores de velocidade (lombadas e lombofaixas) sendo aplicados por quase toda a cidade. Segundo a Secretaria de Segurança e Cidadania de Franca (2017) são realizados estudos técnicos principalmente nos locais mais críticos da cidade de Franca para gerar melhorias na sinalização.

Como a maioria das cidades brasileiras, Franca também sofre quanto à gestão e falta de organização no trânsito, apontando para um crescimento exagerado de sua frota de (75\% em 10 anos, entre 2007 e 2017) segundo dados do Departamento Estadual de Trânsito de São Paulo (Detran), a cidade cresceu de forma desenfreada, não possuindo estrutura adequada para atender uma demanda adicional (Ribeiro, 2017; Jornal da Franca, 2016). Parte da fiscalização das infrações do trânsito francano é praticada pelo Pelotão de Trânsito da Polícia Militar de Franca, entretanto a cidade necessita de mais incentivos e projetos na educação no trânsito (Rodrigues, 2011; Arantes, 2013).

\section{Acidentes}

Ferraz et. al (2012), relata que podemos considerar que um acidente de trânsito é um evento envolvendo dois ou mais veículos, pedestres ou obstáculos fixos no local, que podem causar ferimentos e lesões nas pessoas envolvidas. Os tipos de acidentes (figura 1) podem ser classificados como: (a) Colisão Traseira; (b) Colisão Frontal; (c) Colisão Transversal; (d) Colisão Lateral; (e) Choque; (f) Atropelamento; (g) Tombamento; (h) Capotagem; (i) Engavetamento.

Quanto a gravidade dos acidentes, de acordo com Ferraz et. al (2012) e ABNT (1989), podemos classificados em: (a) Acidentes com vítima fatal; (b) Acidente com feridos sem envolvimento de pedestre; (c) Acidente com feridos envolvendo pedestre; (d) Apenas danos materiais.

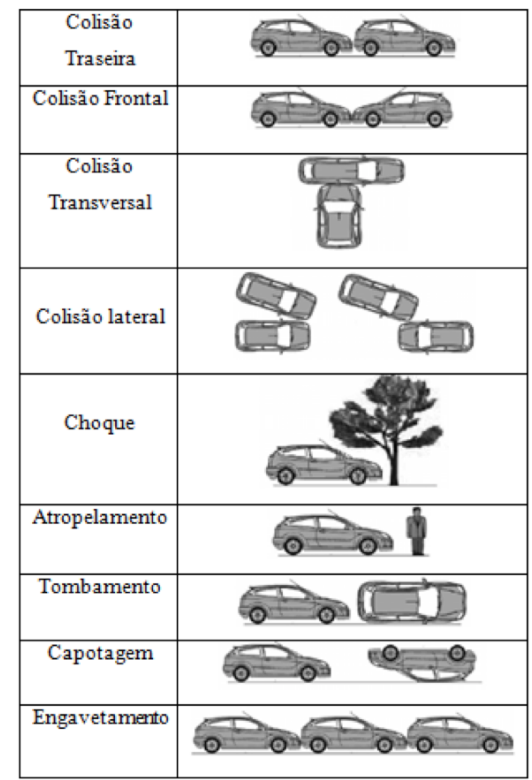


Figura 2: Quantidade de vítimas no trânsito francano de 2016. Fonte: Murari, 2017.

Figura 3: Lombofaixa. Fonte: Prefeitura Municipal de Franca / SP, 2017.
Os acidentes na cidade de Franca/SP são vistos como um problema a ser enfrentado pelos órgãos competentes da cidade, segundo um estudo realizado pelo Movimento Paulista de Segurança no Trânsito, indica que a cidade de São Paulo/SP em 2016 matou menos pessoas que a cidade de Franca/SP, onde o índice de mortes nas ruas francanas foram de aproximadamente 10,2 a cada 100 mil habitantes, e na cidade de São Paulo de aproximadamente 8,2 a cada 100 mil habitantes. Este estudo também indicou que os condutores masculinos são os mais afetados nas ruas de Franca, grande parte são motociclistas. No ano de 2016, foram registradas um total de 34 vítimas, apenas 7 eram vítimas femininas, a figura 2 representa as vítimas que foram à óbito devido ao trânsito de Franca (Murari, 2017).

De acordo com a Prefeitura Municipal de Franca (2017), no ano de 2017 aconteceu uma redução significativa dos acidentes de trânsito, devido a frequentes fiscalizações realizadas pela Polícia Militar e por parte de iniciativas da Secretaria de Segurança e Cidadania em conjunto com a Empresa municipal para o Desenvolvimento de Franca (EMDEF), que adotaram novas medidas para a redução de velocidade. A principal medida adotada foi a implementação de lombadas ou lombofaixas, representadas na figura 3, que têm o objetivo de reduzir a velocidade dos veículos e facilitar a travessia segura dos pedestres de um lado da rua ao outro.
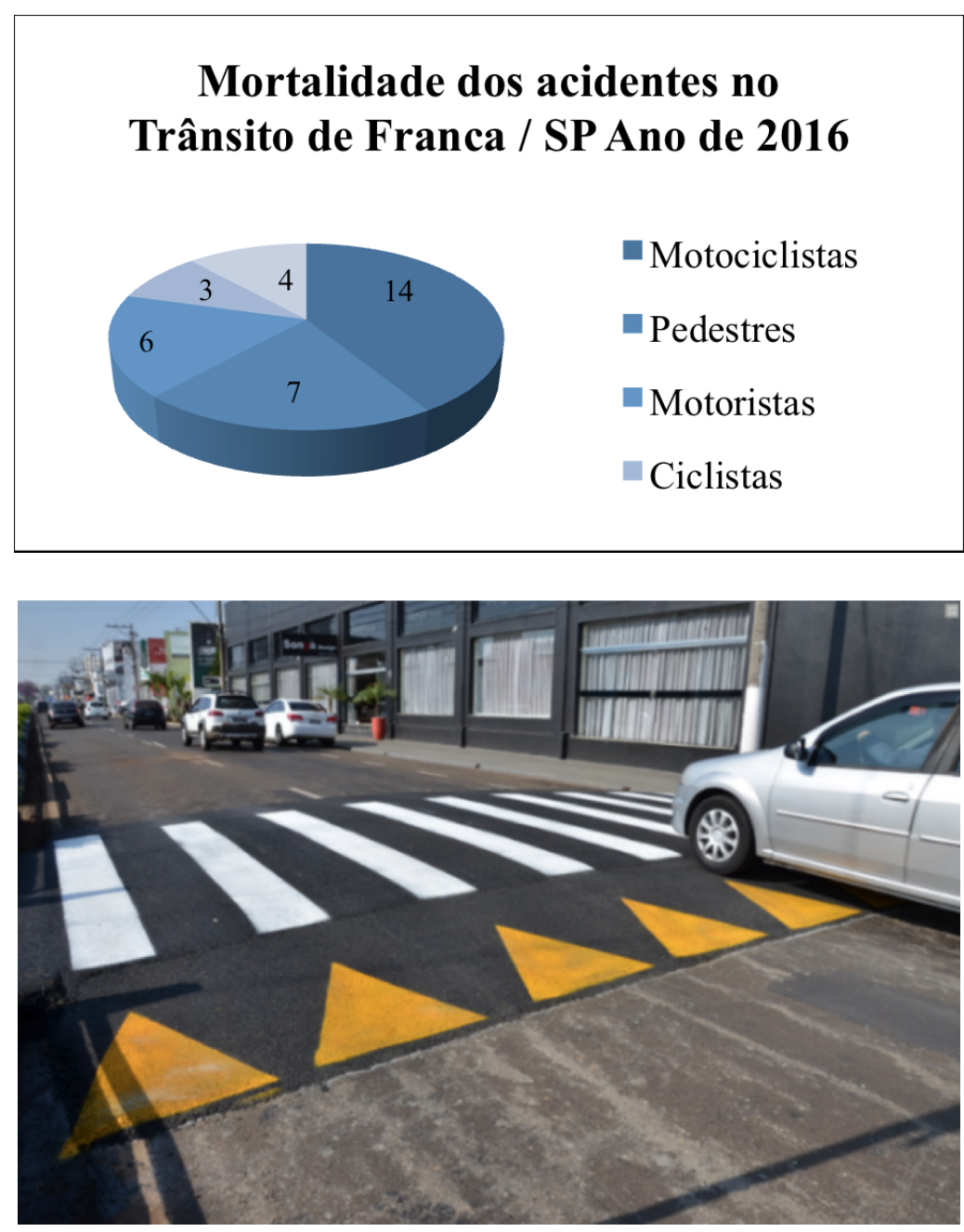
Quadro 1: Principais fatores que contribuem para melhorar a educação e segurança no trânsito. Fonte: Adaptação Ministério das Cidades, departamento SeMob, 2015, cap 4.
Além disso, o Pelotão de Trânsito da Polícia Militar de Franca/SP, coletou dados do mesmo período do ano de 2016 indicando uma redução de aproximadamente 54\% nas vitimas fatais no trânsito francano e cerca de 35\% nas vitimas não fatais (Sales, 2017).

Em 2018 a cidade de Franca/SP voltou a registrar altos índices de acidentes, após um ano que ouve melhorias em relação à sinalização e principalmente na redução de acidentes fatais. (Murari, 2018).

Foram registrados 39 fatalidades apenas no período de Janeiro até o começo de agosto, apontando novamente sérios riscos aos motociclistas e aos condutores masculinos, que representam um número crítico em relação as taxas de acidentes em Franca/SP. (Mendes, 2018)

Entre as 39 fatalidades do trânsito francano 18 mortes são de motociclistas, registros das 39 vítimas 32 são do sexo masculino, de tal forma os dados foram coletados até o início do mês de agosto que já garante o ano mais violento na década do trânsito francano, podendo haver chances de dobrar a quantidade de vítimas fatais decorrentes de acidentes de trânsito em Franca/SP. (Murari, 2018).

\section{Educação no trânsito}

Além do homem, a engenharia de segurança viária apresenta grande influência no comportamento do motorista, pois uma via segura reflete maior confiabilidade e induz redução na ocorrência de acidentes. Com isso aumenta a tendência em reduzir a quantidade de mortes causadas no trânsito, pois esta ação traz o benefício da educação no trânsito. (DIÓGENES, NODARI e LINDAU, 2005)

O quadro 1 representa alguns exemplos de medidas de se obter maior segurança de todos os usuários do espaço viário.

\begin{tabular}{|l|l|}
\hline \multicolumn{2}{|c|}{ Medidas para aumento de segurança - Educação no Trânsito } \\
\hline Sinalização & $\begin{array}{l}\text { Direta; Visibilidade; Iluminação adequada; Pintura de pavimento apre- } \\
\text { sente baixo grau de refletância; }\end{array}$ \\
\hline Vias & $\begin{array}{l}\text { Bom estado; recomenda-se retirar objetos que oculte o pedestre; } \\
\text { Barreiras de proteção }\end{array}$ \\
\hline Interseção & Rotatórias com a intenção de reduzir conflitos entre movimentos \\
\hline Meio de Quadra & Pontos de travessias iluminados \\
\hline Pedestres & $\begin{array}{l}\text { Calçadas niveladas, sem bloqueios, levando a maior acessibilidade à } \\
\text { todos os usuários, principalmente os que apresentam algum tipo de } \\
\text { deficiência; Faixas de segurança, Semáforo exclusivo, Diminuir distân- } \\
\text { cia de travessia }\end{array}$ \\
\hline Velocidade & $\begin{array}{l}\text { Travessias elevadas para resultar na redução da velocidade; estreita- } \\
\text { mento de faixas; Radares. }\end{array}$ \\
\hline
\end{tabular}


Figura 4: Etapas da metodologia de pesquisa. Fonte: Autoria própria.

Figura 5: Representação das avenidas de estudo. Fonte: Google Earth, 2018.

\section{Material e métodos}

Para esse estudo foi desenvolvido uma metodologia com base em questionários e entrevistas, juntamente com uma análise qualitativa e quantitativa da situação. Esse estudo teve, um enfoque na avaliação da segurança viária pela percepção do cidadão francano, seja pedestre, motociclistas e motoristas. A metodologia empregada está baseada resumidamente no fluxograma da figura 4 , uma vez que a mesma retrata as etapas da pesquisa.

O estudo foi direcionado para as seguintes avenidas de Franca: Av. Brasil, Av. Chico Júlio, Av. Dr. Alonso y Alonso, Av. Dr. Hélio Palermo, Av. Major Nicácio, Av. Orlando Dompieri e Av. Presidente Getúlio Vargas (ver figura 5), estão localizadas no município de Franca / SP. A cidade possui aproximadamente 350 mil habitantes. (BRASIL, 2003; IBGE, 2016).

Os pontos referenciais foram escolhidos, devido à classificação de vias principais avenidas, de acordo com a câmara Municipal de Franca (2003), no total são 28 avenidas principais, porém para aplicar esta metodologia foram escolhidas sete avenidas. Vale ressaltar que todas apresentam ligações com uma ou mais avenidas em estudo, como visto na figura 5.
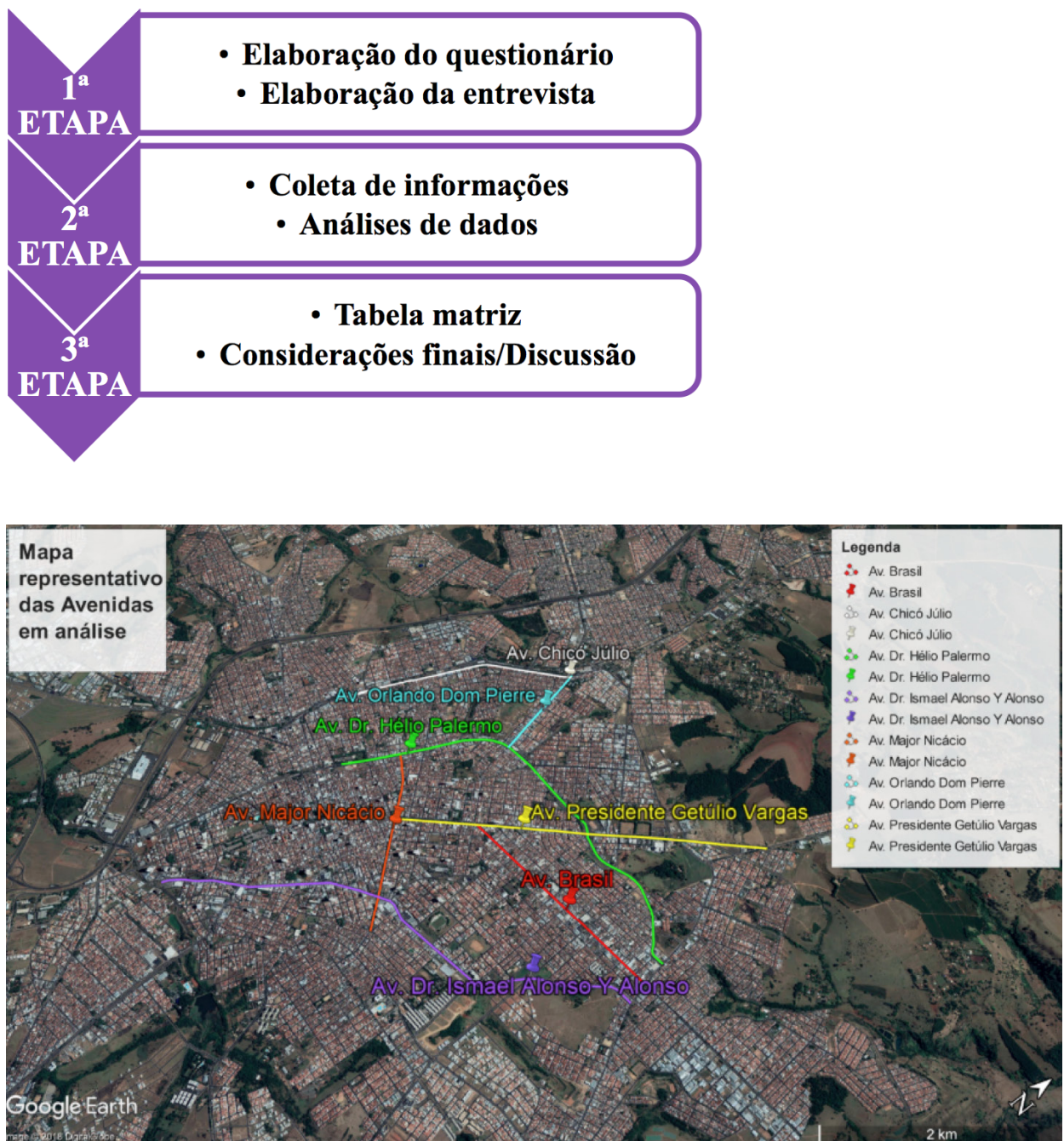
Tabela 1: Extensão das avenidas de estudo. Fonte: Autoria própria com auxílio do Google Maps.

Tabela 2: Quantidade de usuários por avenida de estudo. Fonte: Autoria própria.
A pesquisa foi fundamentada em abordagem pessoal através de entrevistas, por via e-mail e redes sociais, através de questionário e formulário destinado à um grupo específico que utilizam as avenidas do estudo. As perguntas tiveram foco em segurança no trânsito, riscos de acidentes, sinalização, importância da segurança viário e dispositivo auxiliares de redução de velocidade. Assim, puder classificar essas avenidas em questões de segurança e qualidade que oferecem pela percepção dos citadinos que as utilizam.

O estudo foi realizado no período do mês de setembro a outubro de 2018, com a finalidade de coletar dados atualizados, e assim obter maior precisão dos resultados, além de ser um período adequado para pesquisa, ou seja, não é período de férias e feriados.

Os horários de aplicação das entrevistas por abordagem pessoal, foram 08:00 às 14:00 e 16:00 às 19:00 de segunda a sexta, também com a finalidade de obter maior precisão, por ser horário de maior demanda de transporte. Em relação ao "Formulário" disponível pelo Google Docs, este ficou disponível por 17 dias. Assim com ambas conjunto, foram obtidas 204 respostas válidas, além disso, se obteve os dados do comprimento das avenidas em análises de cada trecho das avenidas, representados na tabela 1.

A tabela 2 apresenta a quantidade de usuários que utilizam as avenidas em estudo, em função dos 204 entrevistados, sendo que cada entrevistado poderia escolher mais de uma avenida de uso no seu dia a dia.

\begin{tabular}{lc}
\hline Trecho analisado & Quilometragem \\
\hline Av. Brasil & $2,3 \mathrm{~km}$ \\
Av. Chico Júlio & $2,7 \mathrm{~km}$ \\
Av. Dr. Alonso y Alonso & $5,48 \mathrm{~km}$ \\
Av. Dr. Hélio Palermo & $4,72 \mathrm{~km}$ \\
Av. Major Nicácio & $2,46 \mathrm{~km}$ \\
Av. Orlando Dompieri & $1,12 \mathrm{~km}$ \\
Av. Presidente Getúlio Vargas & $3,57 \mathrm{~km}$ \\
\hline
\end{tabular}

Quantidade de usuários

Av. Brasil 96

Av. Chico Júlio $\quad 90$

Av. Dr. Alonso y Alonso 136

Av. Dr. Hélio Palermo 115

Av. Major Nicácio, $\quad 121$

Av. Orlando Dompieri 56

Av. Presidente Getúlio Vargas 106 
Esta busca de dados tem o propósito de se obter análises, com o pensamento de conquistar uma relação que aborde a segurança no trânsito, oferecidas aos citadinos que utilizam estas avenidas, consideradas entre as principais da cidade de Franca / SP. Para isso foi utilizada planilha eletrônica, com a finalidade de aplicar gráficos com os dados levantados e assim resultar em maior visualização e precisão deste estudo.

É importante ressaltar que algumas mudanças já foram tomadas, como exemplo, a inclusão de faixas elevadas, entre outros, o que influência diretamente nos resultados analisados. Na etapa de tabulação, formulação da tabela matriz, é adequada o seu estudo para que se possa auxiliar em uma possível avaliação da percepção dos francanos na pesquisa abordada.

Contudo, a metodologia aplicada, pretende gerar contribuições, e dar continuidade no estudo, levando aos resultados e análises necessárias para que se possa concluir esta relação do aspecto do trânsito francano relacionada as avenidas da pesquisa através da avaliação da percepção dos usuários.

\section{Resultados}

De acordo com os formulários e entrevistas obtiveram-se os dados de estudos, sendo analisados dados de 204 entrevistados, de forma que cerca de $64,20 \%$ dos entrevistados se classificam em motoristas (131), 19,10\% são motociclistas (39) e $16,70 \%$ pedestres (34). Na figura 6 representa de maneira ilustrativa as avenidas utilizadas pelos entrevistados e a porcentagem de usuários em função do total de entrevistados, com destaque a avenida Dr. Alonso y Alonso com 136 usuários, representando $66,7 \%$ do total de entrevistados.

Em relação à frequência do uso das avenidas de estudo, foi constatado que a maioria dos entrevistados, 28,40\% utilizam as avenidas de estudo com uma frequência de 5 vezes por semana, $17,60 \%$ utilizam 7 vezes na semana, $14,20 \%$ utilizam cerca de 3 a 4 vezes na semana, $11,80 \%$ cerca de 6 vezes semanal, o restante as utiliza 1 vez na semana $(7,80 \%)$ e 2 vezes na semana $(6,0 \%)$.

Figura 6: Representação gráfica das avenidas utilizadas pelos entrevistados. Fonte: Autoria própria.
Em relação à classificação de segurança do trânsito francano pela percepção dos usuários, classificou a segurança nos aspectos: ruim (35,80\%); razoável $(33,40 \%)$; bom $(15,70 \%)$; excelente (0,50\%); não consideram importantes (4,90\%); péssimo $(9,70 \%)$.

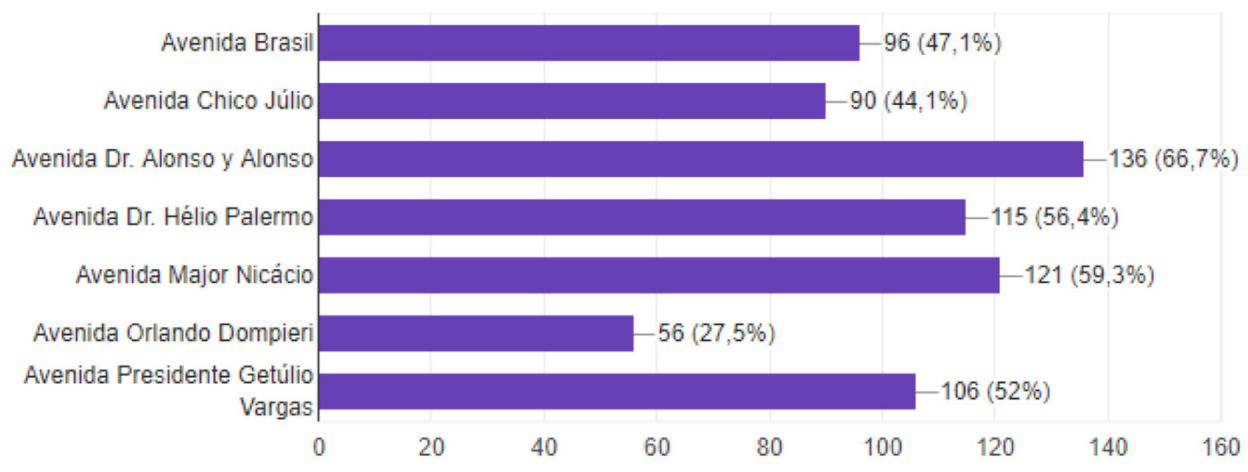


Figura 7: Representação gráfica de situações em que os pedestres passaram. Fonte: Autoria própria.

Figura 8 (embaixo): Relação de acidentes envolvendo os pedestres. Fonte: Autoria própria.

\section{Pedestre}

Como foi abordado na metodologia, foi analisado na maneira em que o usuário se classificaria, nesta parte aponta a visão dos pedestres, que no total foram 34 entrevistados. Na figura 7 representa o gráfico de certas situações em que os pedestres sofreram nas avenidas em análise.

Na figura 7, aponta alguns tópicos de situações em que os pedestres sofreram, como: desrespeito por algum condutor de veículo (buzinas, ofensas, entre outros), resultou em cerca de $50 \%$ passaram por esta situação. Já em relação à situação em que o condutor perdeu a visão do pedestre (situação de ponto cego), ocorreu aproximadamente a $53 \%$. Ainda em relação ao desrespeito de condutores, neste caso com a faixa de pedestre, ocorreu cerca de $73,50 \%$ dos entrevistados. A respeito de situação de risco de acidente ocasionado por condutores de veículos e desrespeito a sinalização semafórica, ocorreu em $82,40 \%$ dos pedestres.

Os pedestres destacaram três pontos importantes no decorrer da entrevista para proporcionar mais segurança: (a) Melhorias nas fiscalizações de trânsito; (b) Melhorias na conscientização de segurança no trânsito; (c) Melhorias na iluminação durante o trajeto.

Na figura 8, representa o gráfico de situações que os pedestres passaram, relacionando os acidentes, ou seja, são as causas que os mesmos sofreram em função dos acidentes ocasionados envolvendo veículos.
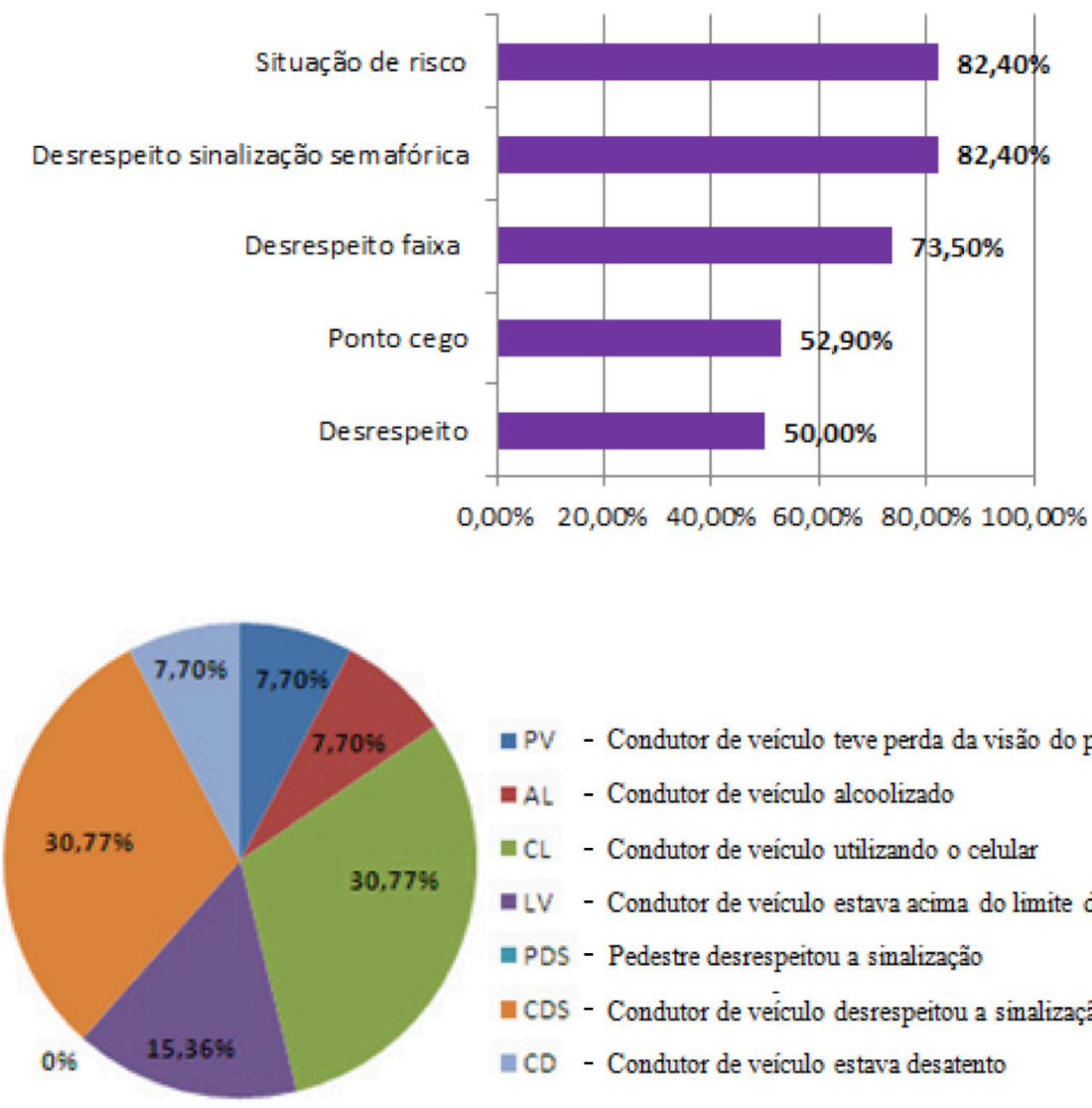

n PV - Condutor de veículo teve perda da visão do pedestre

In AL - Condutor de veículo alcoolizado

= CL - Condutor de veículo utilizando o celular

n LV - Condutor de veículo estava acima do limite de velocidade

n POS - Pedestre desrespeitou a simalização

n $\operatorname{CDS}$ - Condutor de véículo desrespeitou a sinalização

n $\mathrm{CD}$ - Condutor de veículo estava desatento 
Figura 9: Representação gráfica de situações em que os motociclistas passaram/atuaram. Fonte: Autoria própria.

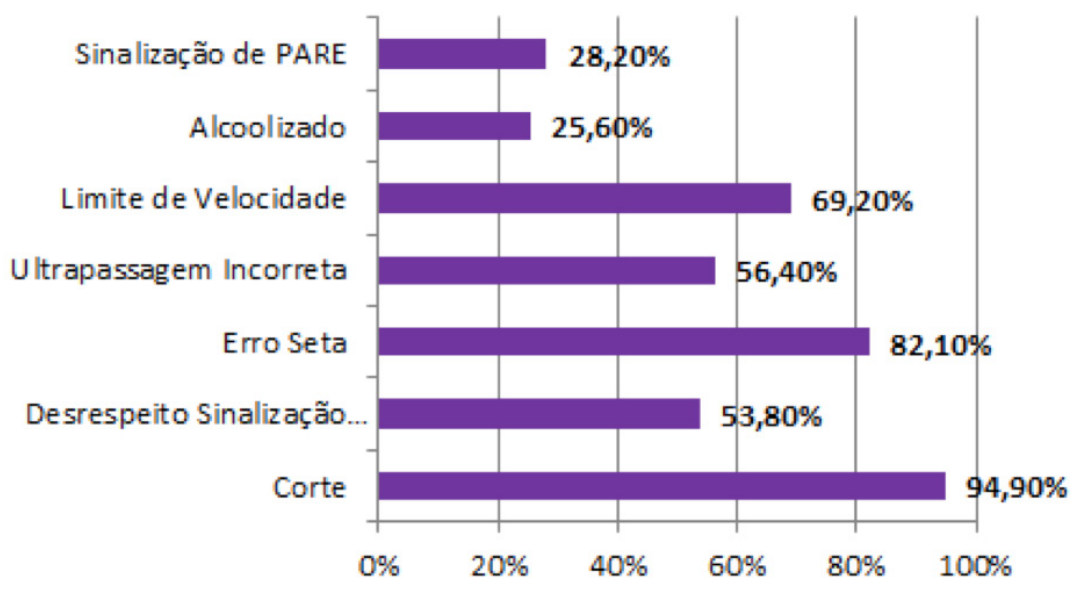

\section{Motociclista}

Como foi abordado na metodologia, foi analisado na maneira em que o usuário se classificaria nesta parte aponta a visão dos motociclistas, que no total foram 39 entrevistados. Na figura 9 representa o gráfico de certas situações em que estes passaram e atuaram.

Na figura 9, aponta alguns tópicos de situações em que os motociclistas atuaram e passaram. Em relação às situações em que eles passaram: cerca de $94,95 \%$ já tiveram seu caminho cortado por outros veículos durante o seu trajeto; $82,10 \%$ sofreram risco de acidentes por erro indicativo de seta, ou falta da mesma, de outro veículo. Analisando o fato de situação em que eles são os atuantes: desrespeito a sinalização semafórica, 53,80\%; ultrapassagem incorreta, pela direita, 56,40\%; excedeu o limite de velocidade permitido, 69,20\%; conduziu alcoolizado, 25,60\%; desrespeito pela sinalização de PARE, $28,20 \%$.

Os motociclistas destacaram três pontos importantes no decorrer da entrevista para proporcionar mais segurança: (a) Melhorias nas fiscalizações de transito; (b) Melhorias na conscientização de segurança no trânsito; (c) Melhorias nas sinalizações de transito.

\section{Motorista}

Como foi abordado na metodologia, foi analisado na maneira em que o usuário se classificaria, nesta parte aponta a visão dos motoristas (veículo carro), que no total foram 131 entrevistados. Na figura 10 representa o gráfico de certas situações em que estes passaram e atuaram.

Na figura 10, aponta alguns tópicos de situações em que os motoristas atuaram e passaram. Em relação às situações em que eles passaram: aproximadamente $97 \%$ já foram cortados por outros veículos durante o seu trajeto; $83,20 \%$ sofreram risco de acidentes por erro indicativo de seta, ou falta da mesma, de outro veículo. Analisando 
Figura 10: Representação gráfica de situações em que os motoristas passaram/atuaram. Fonte: Autoria própria.

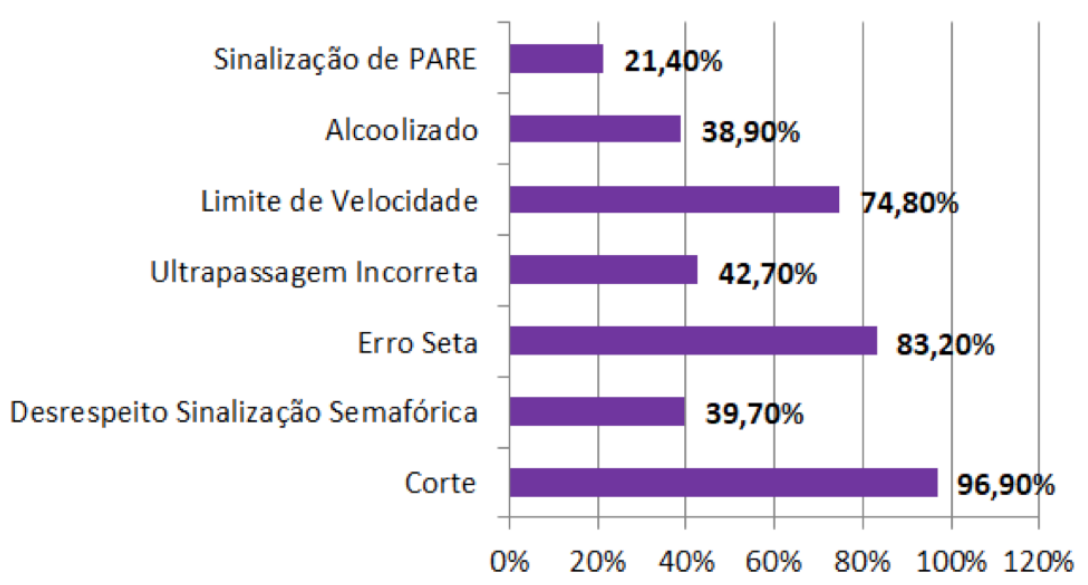

o fato de situação em que eles são os atuantes: desrespeito a sinalização semafórica, 39,70\%; ultrapassagem incorreta, pela direita, 42,70\%; excedeu o limite de velocidade permitido, $74,80 \%$; conduziu alcoolizado, aproximadamente $39 \%$; desrespeito pela sinalização de PARE, $21,40 \%$.

Os motoristas destacaram três pontos importantes no decorrer da entrevista para proporcionar mais segurança: (a) Melhorias nas sinalizações de trânsito; (b) Melhorias nas fiscalizações de trânsito; (c) Melhorias na conscientização de segurança no trânsito.

\section{Descrição das avenidas de estudo}

Diante das avenidas em análise, devem-se observar alguns fatores importantes em cada uma das sete avenidas de estudo, como sinalizações, faixas de rolamento e dispositivos auxiliares a pedestres.

A Av. Brasil (figura 11 a) possui 2,3 km de comprimento, possui duas faixas de rolamento em cada sentido, não sendo visíveis as faixas, assim sendo separado o sentido da avenida por uma faixa em amarelo. Existe sinalização vertical visível, como placas de regulamentação, advertência e orientação, como também sinalizações semafóricas visíveis. Em função da sinalização horizontal, apresenta faixa de pedestre visível nos cruzamentos e não possui lombo faixa ao longo de toda a avenida.

A av. Chico Júlio (figura 11 b) possui 2,7 km de comprimento, com duas faixas de rolamento visível em alguns pontos e três faixas de rolamento visível em outros pontos em cada sentido da avenida, sendo separados os sentidos da avenida por um canteiro central. Apresenta sinalização vertical como placa de regulamentação, advertência, orientação e educativas, assim como também sinalizações semafóricas visíveis. Em função da sinalização horizontal possui faixa de pedestre visível nos cruzamentos. Em alguns pontos da avenida possui lombo faixas que auxilia o pedestre e também reduz a velocidade dos veículos. 


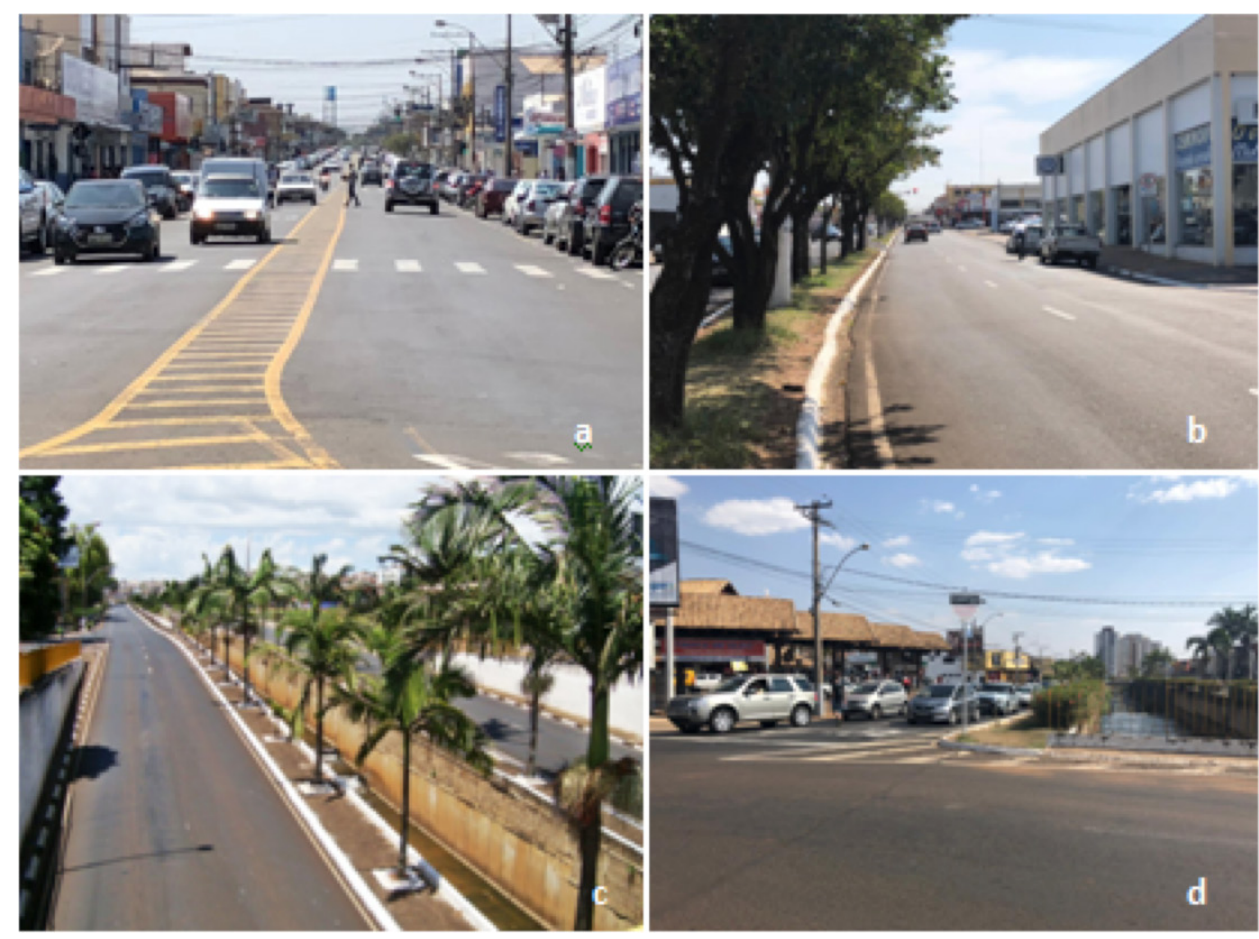

Figura 11: Representação das avenidas de estudo $a ; b ; c ; d$. Fonte: Autoria própria.
A av. Dr. Hélio Palermo (figura 11 c) possui 4,72km de comprimento, possui duas faixas de rolamento em cada sentido, sendo que em boa parte a faixa apresenta de modo visível. Em alguns pontos da avenida apresentam rotatórias a fim de reduzir pontos de conflito entre veículos. Possui sinalização vertical visível, como placas de regulamentação, advertência, orientação, educativas e placas de obras, também existem sinalizações semafóricas visíveis. Possui sinalização horizontal em quase todo seu comprimento como faixas de pedestres. Em alguns pontos não possui sinalizações, e também não apresenta lombo faixas em pontos que há necessidade da implementação do dispositivo.

A av. Dr. Ismael Alonso y Alonso (figura $11 \mathrm{~d}$ ) possui 5,48km de comprimento, com duas faixas de rolamento visível em cada sentido da avenida. Em alguns pontos possui rotatórias a fim de reduzir pontos de conflito entre veículos. Apresenta boa sinalização vertical em quase toda a avenida, como placas de regulamentação, advertência, orientação, educativas e placas de obras, existem também sinalizações semafóricas visíveis. Como sinalização horizontal apresenta faixas de pedestre em boa parte da avenida, deixando alguns pontos necessitado do mesmo.

A av. Major Nicácio (figura 12 a) possui 2,46 km de comprimento, com duas faixas de rolamento visível em cada sentido da avenida, sendo separado o sentido da avenida por um canteiro central. Apresenta sinalização vertical com boa visibilidade, como placas de regulamentação, placas de advertência e identificação, como também existem sinalizações semafóricas visíveis. Em relação a sinalização horizontal, possui faixas de pedestres visível, não apresentando nenhuma lombo faixa em todo o comprimento da avenida. 
Figura 12: Representação das avenidas de estudo a;b;c. Fonte: Autoria própria.

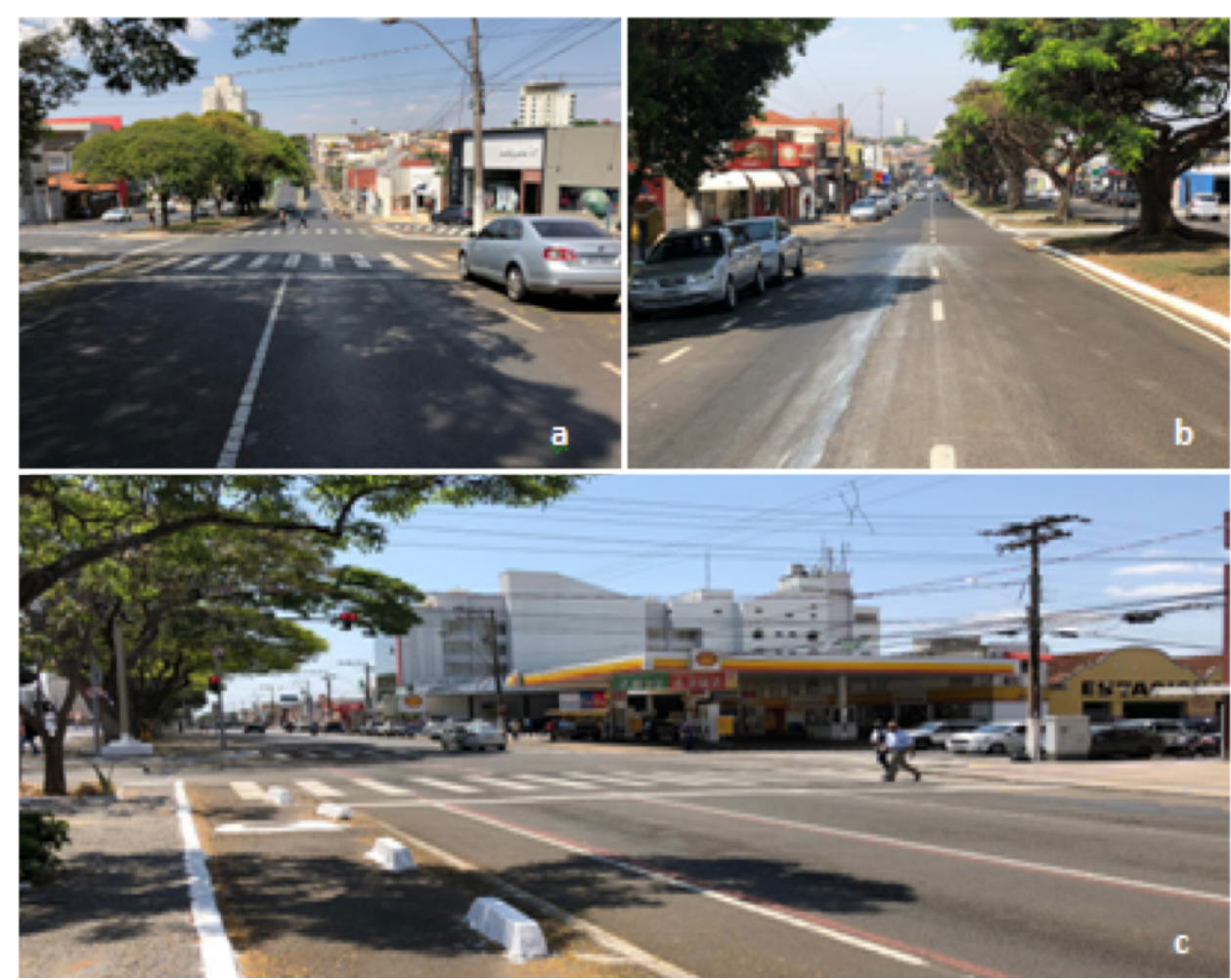

A av. Orlando Dompieri (figura $12 \mathrm{~b}$ ) possui $1,12 \mathrm{~km}$ de comprimento, com duas faixas de rolamento visível em cada sentido da avenida, sendo separado o sentido da avenida por um canteiro central. Apresenta sinalização vertical visível, como placas de regulamentação, advertência e orientação, como também existem sinalizações semafóricas visíveis. Em relação a sinalização horizontal não apresenta faixas de pedestre e também não apresenta lombo faixas.

A av. Presidente Getúlio Vargas (figura 12 c) possui 3,57 km de comprimento, com três faixas de rolamento visível em cada sentido da avenida, sendo separado o sentido da avenida por um canteiro central. Apresenta sinalização vertical visível, como placas de regulamentação, advertência, orientação e placas de obras, como também existem sinalizações semafóricas visíveis. Em relação a sinalização horizontal, apresenta faixas de pedestres visível em todo o seu comprimento de avenida, lombo faixas e faixa de ciclista aos dias de domingo.

\section{Acidentes}

De acordo com a metodologia empregada, podem-se obter os resultados de análises de ocorrência de acidentes e o tipo do mesmo, foi constatado que aproximadamente 37\% do total de entrevistados sofreram pelo menos um acidente nas avenidas de estudo. Com estes dados, foi possível criar tabela que apresentam os acidentes ocorridos em cada avenida em análise, abordando o horário do ocorrido, o tipo de acidente e a severidade desses acidentes. Os termos abordados na tabela matriz estão ilustrados no quadro 2.

Também foi observado que aproximadamente $36,40 \%$ dos pedestres entrevistados apresentaram alguma sequela, relacionada aos tipos de acidentes abordados na tabela matriz. 


\begin{tabular}{|c|c|c|c|c|c|c|c|}
\hline \multicolumn{8}{|c|}{ HORÁRIO } \\
\hline Classificação & $06: 00-11: 59$ & 12:00-14:59 & 15:00-16:59 & 17:00-19:59 & $20: 00-22: 59$ & $23: 00-02: 59$ & 03:00-5:59 \\
\hline Pedestre & 6 & 4 & 2 & 0 & 0 & 0 & 1 \\
\hline Motociclista & 5 & 2 & 3 & 7 & 1 & 0 & 0 \\
\hline Motorista & 16 & 7 & 14 & 31 & 5 & 1 & 1 \\
\hline \multicolumn{8}{|c|}{ LOCAL } \\
\hline Classificação & A & B & C & D & $E$ & $\mathbf{F}$ & G \\
\hline Pedestre & 4 & 1 & 4 & 2 & 1 & 0 & 1 \\
\hline Motociclista & 5 & 1 & 3 & 0 & 3 & 4 & 2 \\
\hline Motorista & 6 & 12 & 23 & 10 & 9 & 4 & 11 \\
\hline \multicolumn{8}{|c|}{ TIPO DE ACIDENTE } \\
\hline Classificação & CF & $\mathrm{CL}$ & CT & $\mathrm{CH}$ & CTV & \multicolumn{2}{|c|}{ AT } \\
\hline Pedestre & 0 & 0 & 0 & 0 & 0 & \multicolumn{2}{|c|}{13} \\
\hline Motociclista & 1 & 7 & 6 & 0 & 4 & \multicolumn{2}{|c|}{0} \\
\hline Motorista & 8 & 19 & 28 & 9 & 11 & \multicolumn{2}{|c|}{0} \\
\hline \multicolumn{8}{|c|}{ SEVERIDADE } \\
\hline Classificação & AVF & \multicolumn{2}{|c|}{ ATR } & \multicolumn{2}{|c|}{ ACF } & \multicolumn{2}{|c|}{ ADM } \\
\hline Pedestre & 0 & \multicolumn{2}{|c|}{10} & \multicolumn{2}{|c|}{1} & \multicolumn{2}{|c|}{2} \\
\hline Motociclista & 0 & \multicolumn{2}{|c|}{0} & \multicolumn{2}{|c|}{13} & \multicolumn{2}{|c|}{5} \\
\hline Motorista & 0 & \multicolumn{2}{|c|}{13} & \multicolumn{2}{|c|}{17} & \multicolumn{2}{|c|}{45} \\
\hline
\end{tabular}

Tabela 10 (topo): Matriz de acidentes.Fonte: Autoria própria.

Quadro 2 (dir.): Descrição da tabela matriz. Fonte: Autoria própria.

\begin{tabular}{|l|l|}
\hline \multicolumn{2}{|l|}{ LOCAL } \\
\hline A & Av. Brasil \\
\hline B & Av. Chico Júlio \\
\hline C & Av. Dr. Alonso y Alonso \\
\hline D & Av. Dr. Hélio Palermo \\
\hline E & Av. Major Nicácio, \\
\hline F & Av. Orlando Dompieri \\
\hline G & Av. Presidente Getúlio Vargas \\
\hline & TIPO DE ACIDENTE MOTORISTA / MOTOCICLISTA \\
\hline CF & Colisão Frontal \\
\hline CL & Colisão Lateral \\
\hline CT & Colisão Traseira \\
\hline CH & Choque \\
\hline CTV & Colisão Transversal \\
\hline AT & Atropelamento \\
\hline \multicolumn{2}{|c|}{} \\
\hline AVF & Acidente com vítima fatal \\
\hline ATR & Acidente com ferido envolvendo pedestre \\
\hline ACF & Acidente com ferido sem envolvimento de pedestre \\
\hline ADM & Acidente com apenas danos materiais \\
\hline
\end{tabular}




\section{Discussão}

\section{Fatores gerais}

Os motoristas se destacaram por apresentarem o maior percentual de acidentes, cerca de $23,20 \%$ do total de entrevistados, em segundo os motociclistas em aproximadamente $8,40 \%$ e por último os pedestres em torno de 5,40\%.

As avenidas de estudos que apresentaram o maior percentual e maior quantidade de acidente, tanto para motorista, motociclista e pedestre, foram as Av. Alonso Y Alonso e Av. Brasil, representadas na figura 32 e 35 respectivamente. Em relação ao período de maior ocorrência de acidentes, na classificação geral, foram os das 06:00 às $11: 59,12: 00$ às $14: 59$ e $17: 00$ às 19:59.

Os tipos de acidentes que mais ocorreram foram à colisão traseira (motorista), colisão lateral (motociclista) e atropelamento (pedestre). No quesito de severidade dos acidentes, o que tiveram maior percentual foi o de acidentes apenas com danos materiais (motorista), acidente com ferido sem envolvimento de pedestre (motociclista) e acidente com ferido envolvendo pedestre (pedestre).

\section{Fatores específicos}

Com os dados obtidos, observou que $47(23,20 \%)$ motoristas sofreram um ou mais tipos de acidentes (75 acidentes) e também representam o maior percentual em comparação aos pedestres e motociclistas. A avenida que mais ocorreu acidente foi a Av. Dr. Alonso Y Alonso, 23 acidentes (30,67\%) e avenida que menos ocorreu acidente foi a Av. Orlando Dompieri, 4 acidentes (5,33\%). Com relação a avenida de maior quantidade de acidente, no caso a Av. Dr. Alonso Y Alonso, o horário que teve maior ocorrência foi das 17:00 às 19:59 (12 acidentes), período noturno, o tipo de acidente que mais ocorreu nesta avenida de estudo foi o de colisão traseira (7 acidentes) e por fim, em relação a severidade dos acidentes desta avenida foi o do tipo de acidentes com apenas danos materiais, 13 acidentes.

Com os dados obtidos, observou que $17(8,4 \%)$ motociclistas sofreram um ou mais tipos de acidentes (18 acidentes). A avenida que mais ocorreu acidente foi a Av. Brasil, 5 acidentes $(27,77 \%)$ e avenida que menos ocorreu acidente foi a Av. Dr. Hélio Palermo, não ocorreu nenhum acidente. Com relação à avenida de maior quantidade de acidente, no caso a Av. Brasil, o horário que teve maior ocorrência foi das 17:00 às 19:59 (2 acidentes), período noturno, o tipo de acidente que mais ocorreu nesta avenida de estudo foi o de colisão traseira ( 2 acidentes) e colisão transversal ( 2 acidentes) e por fim, em relação à severidade dos acidentes desta avenida foi o do tipo de acidentes com apenas danos materiais, 4 acidentes.

Com os dados obtidos, observou que $11(5,4 \%)$ pedestres sofreram um ou mais tipos de acidentes (13 acidentes). As avenidas que mais ocorreram acidentes foram a Av. Brasil e Avenida Dr. Alonso Y Alonso, com 4 acidentes/avenida (30,78\%), no caso o tipo de acidente é atropelamento, e a avenida que menos ocorreu acidente foi a Av. Orlando Dompieri, não ocorreu nenhum acidente. Com relação à avenida de maior quantidade de acidente, no caso a Av. Brasil, o horário que teve maior ocorrência foi das 12:00 às 14:59 (3 acidentes) e na Av. Alonso Y Alonso foi o período das 06:00 
às 11:59 (3 acidentes), e por fim, em relação à severidade dos acidentes, o tipo de acidente que ocorreu nestas avenidas foi o acidente com ferido envolvendo pedestre, Av. Brasil com 2 acidentes e Av. Alonso Y Alonso 3 acidentes.

Por fim, em relação à classificação de segurança oferecido pelo trânsito francano, segunda a percepção dos mesmos, os maiores percentuais apontaram que, cerca de 73 (35,80\%) entrevistados classificam ruim, e 68 (33,40\%) classificam razoável.

\section{Conclusão}

No decorrer da pesquisa bibliográfica, vimos que a principal causa dos acidentes é o excesso de velocidade nas vias. Os resultados obtidos por meio da metodologia abordada relataram que motoristas e motociclistas excedem o limite de velocidade das avenidas em estudo. Em relação à velocidade, dos 131 motoristas entrevistados, $75 \%$ deles já excederam o limite de velocidade. Já em relação aos 39 motociclistas, $70 \%$ já cometeram esse tipo de infração. Além disso, analisou-se a percepção dos entrevistados em função das necessidades de melhorias que as avenidas em estudo demandam. No geral a pesquisa ressaltou que os 105 entrevistados sugeriram melhorias na sinalização, enquanto 166 entrevistados apontaram necessidades no aumento de conscientização do trânsito. Vale ressaltar que na pesquisa os entrevistados poderiam optar por mais de uma melhoria aplicada nas avenidas em estudo.

Diante de todo o quadro apresentado, percebeu-se que pela avaliação da percepção dos moradores de Franca, usuários das avenidas em estudo, consideram que estas avenidas, precisam apresentar melhorias, para que se possa obter maior segurança viária, principalmente a Avenida Brasil e Avenida Alonso y Alonso, como foram apontados com as maiores porcentagens de acidentes.

No caso da Avenida Brasil, onde a maioria faz trajeto irregular, ou seja, cruzam no sentido da contramão, o que é um grande risco tanto para o motorista/motociclista e pedestre, diante desta situação, uma possível solução seria a construção de um canteiro que separa os dois sentidos da avenida junto com a implementação de dispositivos de redução de velocidade, como faixas elevadas para facilitar o cruzamento dos pedestres de um lado ao outro e também diminuir a velocidade dos veículos. Outra possibilidade seria o uso de tachões no sentido longitudinal da avenida, com o mesmo intuito de evitar que condutores de veículos façam uma travessia incorreta para o sentido oposto. Em relação ao estudo da Avenida Alonso y Alonso, uma possível melhoria seria a inclusão de faixas elevadas, para poder provocar a redução na velocidade e proporcionar acessibilidade aos pedestres.

Através do estudo realizado foi apontado que os riscos a acidentes estão presentes aos moradores de Franca, principalmente em horários de pico, onde o fluxo de veículos é mais intenso e a possibilidade de ocorrências são maiores. Podemos considerar que esses riscos estão sujeitos ao fato do aumento acelerado da frota de veículos da cidade e pelo pouco investimento realizado em estruturas que acolheriam tal volume. Desta forma pode-se considerar que tenha passado a hora de mudar o pensamento em relação aos meios de locomoção interurbanos, ou seja, tentar utilizar os investimentos voltados em modos de transportes que possa ter uma maior otimização dos deslocamentos, tais como transportes públicos ou até mesmo carsharing (compartilhamento de veículos). 
Esses meios alternativos podem não apenas contribuir para a redução aos riscos de acidentes, mas também diminuir a severidade dos mesmos, devido a menor exposição de pessoas, assim proporcionando um tráfego mais seguro a todos.

\section{Referências bibliográficas}

ARANTES. E. Polícia Militar desmente indústria da multa de trânsito em Franca. 2013. Disponível em: <http://gcn.net.br>. Acesso em: 30 set. 2018.

ASSOCIAÇÃO BRASILEIRA DE NORMAS TÉCNICAS. NBR 10697: Pesquisa de acidentes de trânsito: Rio de Janeiro, 1989.

BRASIL. Decreto Lei Complementar $n^{\circ}$ 57, de 18 de agosto de 2003. Altera dispositivos da Lei Complementar $n^{\circ} 48$, de 10 de dezembro de 1984. Congresso Nacional. Disponível em: <http://www.planalto.gov.br/>. Acesso em: 30 set. 2018.

Datasus - Ministério da Saúde. Estatísticas vitais. 2014. Disponível em: <https://www2.datasus. gov.br/DATASUS/index.php>. Acesso em: 10 jun. 2018.

Departamento de Polícia Militar do Estado de São Paulo. 2018. Disponível em: <http://www. policiamilitar.sp.gov.br/>. Acesso em: 10 jun. 2018.

DETRAN - Departamento de Estadual de Trânsito. Detran/SP promove ações educativas na semana nacional de trânsito em Franca/SP. 2015. Disponível em: <https://www.detran. sp.gov.br>. Acesso em: 10 jun. 2018.

DIÓGENES, M. C.; NODARI, C. T.; LINDAU, L. A. Priorização de ações de segurança viária na perspectiva dos motoristas. In: CONGRESSO DE PESQUISA E ENSINO EM TRANSPORTES, 2005, Recife. Anais ANPET XIX. Recife: Universidade Federal do Rio Grande do Sul, 2005. p. 969-979.

FERRAZ, A. C. P. et al. Segurança viária. 1. ed. São Carlos: Suprema Gráfica e Editora Ltda, 2012.

Google Earth. Acesso em: 13 out. 2018.

Google Maps. Trecho da Avenida Rio Branco, estação. 2017. Disponível em: <https://www. google.com.br/maps>. Acesso em: 30 set. 2018.

IBGE - Instituto Brasileiro de Geografia e Estatística. Censo populacional. 2016. Disponível em: $<$ https://cidades.ibge.gov.br/brasil/sp/franca/panorama>. Acesso em: 30 set. 2018.

Jornal da Franca. Frota de Franca já passa de 239 mil e cidade ganha 6 mil veículos novos por ano. 2016. Disponível em: <http://jornaldafranca.com.br>. Acesso em: 30 set. 2018.

MARTINS. C. B. G.; JORGE. M. H. P. M. A criança, o adolescente e o trânsito: algumas reflexões importantes. Revista da Associação Médica Brasileira, Elsevier Editora Ltda, v.59, n.3, p. 199-208, mai. - jun. 2013.

MENDES. R. A. Conscientização no trânsito. Franca, 2018. Conferência realizada no Teatro do Júri - Universidade de Franca, em 16 ago. 2018.

Ministério das Cidades - Departamento SeMob - Secretaria Nacional de Transporte e da Mobilidade Urbana. PlanMob: caderno de referência para elaboração de plano de mobilidade urbana. Brasil, 2015. Cap.4, p 70.

Ministério da Saúde. Projeto vida no trânsito. 2018. Disponível em: <http://portalms.saude.gov. br/>. Acesso em: 10 jun. 2017.

MURARI. M. Noite concentra maior número de mortes no trânsito de Franca. 2018. Disponível em: <https://www.gcn.net.br/>. Acesso em: 17 jun. 2018.

MURARI. M. Trânsito de Franca mata mais que o de São Paulo. 2017. Disponível em: <https:// www.gcn.net.br/>. Acesso em: 17 jun. 2018. 
Prefeitura Municipal de Franca. Prefeitura amplia instalações de lombofaixas. 2017. Disponível em: <https://www.franca.sp.gov.br/>. Acesso em: 17 jun. 2018.

RIBEIRO. C. Frota cresce 75\% em 10 anos e complica trânsito de Franca. 2017. Disponível em: <http://gcn.net.br>. Acesso em: 30 set. 2018.

RODRIGUES. D. Polícia volta a fiscalizar infrações em ruas e avenidas de Franca. 2011. Disponível em: <http://gcn.net.br>. Acesso em: 30 set. 2018.

Sales. P. Franca reduz acidentes com lombadas. 2017. Disponível em: <http://novacidade.com>. Acesso em: 17 jun. 2018.

Secretaria de Segurança e Cidadania de Franca. Novo semáforo para rua da Cidade Nova. 2017. Disponível em: <https://www.franca.sp.gov.br/noticias/seguranca-e-cidadania/novo-semaforo-para-para-rua-da-cidade-nova>. Acesso em: 30 set. 2018.

World Health Organization. Global status report on road safety: time for action. 2009. 